\title{
The Circulating Level of IL-1 $\beta$ in Patients with Age- related Macular Degeneration (AMD) in Yogyakarta: Characteristics to Disease Activity
}

\author{
Supanji ${ }^{*}$, Ayudha Bahana Ilham Perdamaian ${ }^{1,2}$, Anindita Dianratri ${ }^{1}$, \\ Muhammad Eko Prayogo ${ }^{1}$, Muhammad Bayu Sasongko ${ }^{1}$, Firman Setya \\ Wardhana ${ }^{1}$, Tri Wahyu Widayanti ${ }^{1}$, Angela Nurini Agni ${ }^{1}$, Chio Oka ${ }^{3}$ \\ ${ }^{I}$ Department of Ophthalmology, Faculty of Medicine, Gadjah Mada University, Yogyakarta, Indonesia \\ ${ }^{2}$ Laboratory of Genetics and Breeding, Faculty of Biology, Gadjah Mada University, Yogyakarta, Indonesia \\ ${ }^{3}$ Laboratory of Gene Function in Animals, Nara Institute of Science and Technology, Takayama, Ikoma, Nara, \\ Japan \\ *Corresponding author. Email: supanji@mail.ugm.ac.id
}

\begin{abstract}
Age-related Macular Degeneration (AMD) is leading factors for blindness and impaired visual acuity in developed countries. It is importance to study the dynamic of cytokines concentration during the exudative event of AMD to contribute in the future drugs inventions. This research aims to investigate the IL-1 $\beta$ profiles in plasma of exudative AMD patients. In this cross-sectional study, blood plasma samples from 17 AMD patients and 23 age-matched were collected. Samples were examined for IL-1 $\beta$ inflammatory cytokines using a commercially available ELISA. Acquired data were log transformed to normalize the outlier prior student T-test (SPSS software). Based on recent research, there is a statistically difference of IL-1 $\beta$ among AMD patients and control. IL-1 $\beta$ concentration were higher at control. Detection of high level of inflammatory cytokines supports a role for inflammation in AMD pathogenesis.
\end{abstract}

Keywords: Age-related macular degeneration, inflammation, inflammatory cytokines

\section{INTRODUCTION}

Neovascular or wet Age-related Macular Degeneration (AMD) is recognized by retinal pigment epithelium (RPE) and photoreceptor (cone and rod) depletion, drusen deposition, and neovascularization in the central retina that compromise central visual field which possibility leads to full blindness [1], [2]. Cell density is reduced because the swelling process compromises the RPE cohesion and homeostasis. Genetics and ethnicity are highly contributing to the onset of AMD. There is only a drug to halt AMD progression but not to cure the manifestation.

Study on Indonesian population with Neovascular AMD show high association to genetics [3] and lifestyle [4]. ARMS2 and CFH increase susceptibility to AMD while hypertension and smoking status is risk factors.
Many pathways are involved in AMD development and progression, one of which is the inflammatory pathway [5], [6]. The study of inflammatory cytokines level during the exudative phase of AMD is necessary to understand its contribution to AMD pathogenesis. Interleukin-1 $\beta$ $(\mathrm{IL}-1 \beta)$ is one of the important members of proinflammatory cytokine. Interleukin- $1 \beta$ have many physiological functions [7], [8].

IL-1 $\beta$ has an importance role in health conditions i.e., regulation of feeding, sleep, and temperature. However, excess expression of IL- $1 \beta$ is viewed in osteoarthritis, neuropathic pain, multiple sclerosis rheumatoid arthritis, vascular disease, inflammatory 
bowel disease, and Alzheimer's disease in different states.

This research aims to investigate the IL-1 $\beta$ profiles in circulating blood plasma of wet AMD subjects in Yogyakarta

\section{MATERIALS AND METHODS}

This cross-sectional study utilized blood plasma samples from 16 AMD patients and 23 age-matched non-AMD individuals. Patient and control were recruited at three different hospitals in Yogyakarta.

In this research, ethics was approved by MHREC, Faculty of Medicine, Public Health and Nursing (FKKMK) UGM (EC no. KE/FK/0137/EC/2021). The screening was performed from 2018 until 2019. Informed consent was explained and signed by all patients prior the ophthalmic test and blood sampling. Patient comorbid with other retina disease was excluded to minimize the interference of other IL-1 $\beta$ pathways.

Visual acuity test, fundus photographs, and optical coherence tomography (OCT) was performed by vitreo-retina specialized doctors to diagnose AMD or to verify health eye in control.

Inflammatory cytokines (IL-1 $\beta$ ) identification used a commercially available ELISA kit. Acquired data were log-transformed to normalize the outlier prior student T-test (SPSS software [9].

\section{RESULT AND DISCUSSION}

In this research, the baseline characteristic of AMD and control was not statically different (Table 1.). The number of female and male participants of both groups was proportional. The age structure of both group members was relatively the same except for the 80 years old and older sub-group.

Based on current result, the mean of IL-1 $\beta$ concentration between AMD and the control group was significant $(p=0.047)$. Interestingly, we found that Interleukin- $1 \beta$ concentrations were higher at the control group compared to the AMD group (Table 2.).

IL- $1 \beta$ is a prominent pro-inflammatory cytokine that induce an innate immune response similar to AMD pathogenesis since IL-1 $\beta$ could induce proapoptotic protein expression [10].

The result did not correlate with the previous studies that showed higher IL-1 $\beta$ concentration in AMD subjects [11], We hypothesized that other factors might play roles in the result of our study. The low IL-1 $\beta$ concentration might occur because the patient already at the late phase of the disease manifestation. It is possible that IL-1 $\beta$ was upregulated by other cytokines to prevent overstimulation of apoptosis and swelling in the RPE.

Further research using the more sensitive approach and more patients in exact similar disease phase might give a better understanding of the effect of IL-1 $\beta$ circulation level in AMD pathogenesis.

Table 1. Baseline data of AMD patient and healthy group

\begin{tabular}{|c|c|c|c|c|c|}
\hline Variable & Group & $\begin{array}{c}\text { AMD } \\
(\%)\end{array}$ & $\begin{array}{c}\text { No AMD } \\
(\%)\end{array}$ & p-value & Root \\
\hline \multirow[t]{2}{*}{ Gender } & Male & 58 & 52 & 0.301 & 1.177 \\
\hline & Female & 42 & 46 & & \\
\hline \multirow{4}{*}{$\begin{array}{l}\text { Age } \\
\text { (years } \\
\text { old) }\end{array}$} & $<59$ & 23 & 8 & 0.235 & . \\
\hline & $60-69$ & 35 & 52 & & \\
\hline & $70-79$ & 35 & 30 & & . \\
\hline & $>80$ & 5 & 8 & & . \\
\hline
\end{tabular}

Table 2. The IL-1 $\beta$ circulation level in amd and healthy group

\begin{tabular}{cccc}
\hline $\begin{array}{c}\text { Cytokin } \\
\text { es }\end{array}$ & AMD (\%) & No AMD (\%) & p-value \\
\hline IL-1 $\beta$ & $628 \mathrm{pg} / \mathrm{mL}$ & $4,476.62 \mathrm{pg} / \mathrm{mL}$ & 0.047 \\
& \pm 644.762 & \pm 15216.61 & \\
& & & \\
\end{tabular}

\section{CONCLUSION}

IL-1 $\beta$ showed a significant difference between both study groups. cytokines showed higher concentration in control compared to AMD group. Further investigation might be necessary to confirm the results.

\section{AUTHORS' CONTRIBUTIONS}

SS (Principal Investigator): study conceptualization, methodology, research funding application, data collection and investigation, writing- reviewing and editing, supervision. ABIP: data collection, writing- original draft. AD: data analysis, writing- original draft. MBS: data collection and investigation, data interpretation, writingreviewing. FSW: data collection and investigation, writing- reviewing. MEP: data collection and investigation, writing- TWW: data collection and 
investigation, writing- reviewing. ANA: data collection and investigation, writing- reviewing. CC: conceptualization, data interpretation, writingreviewing and editing.

\section{ACKNOWLEDGMENTS}

The authors want to acknowledge Universitas Gadjah Mada for Providing RTA research grant (No. 1655/UN1/ DITLIT/DIT-LIT/PT/2020).

\section{REFERENCES}

[1] H. Charles-Messance, G. Blot, A. Couturier, et al., IL-1 $\beta$ induces rod degeneration through the disruption of retinal glutamate homeostasis, J Neuroinflammation 17(1) (2020).

DOI: https://doi.org/10.1186/s12974-019-1655-5

[2] T. Sato, M. Takeuchi, Y. Karasawa, et al., Comprehensive expression patterns of inflammatory cytokines in aqueous humor of patients with neovascular age-related macular degeneration, Scientific Reports 9 (2019) $19447 . \quad$ DOI: https://doi.org/10.1038/s41598-019-55191-X

[3] S. Supanji, D.F. Romdhoniyyah, M.B. Sasongko, et al., Associations of ARMS2 and $\mathrm{CFH}$ gene polymorphisms with neovascular age-related macular degeneration, Clinical Ophthalmology (Auckland, N.Z.) 15 (2021) 1101-1108. DOI:

https://doi.org/10.2147/OPTH.S298310

[4] S. Supanji, A.B.I. Perdamaian, R. Aulia, et al., Smoking as a risk factor for rs10490924 variant age-related macular degeneration in Yogyakarta, Indonesia, Malaysian Journal of Medicine and Health Sciences 16 (2020) (SUPP15).

[5] S. Supanji, A.B.I. Perdamaian, A. Dianratri, et al., HtrA1 serine protease expression levels on age-related macular degeneration (AMD) patients in Yogyakarta, in: Proceedings of the 3rd International Conference on Bioinformatics, Biotechnology, and Biomedical Engineering (BioMIC 2020), 28(02004), 2020. DOI: https://doi.org/10.1051/bioconf/2020280200 $\underline{4}$
[6] W. Tan, J. Zou, S. Yoshida, B. Jiang, Y. Zhou, The role of inflammation in agerelated macular degeneration, International Journal of Biological Science 16(15) (2020) 2989-3001.

DOI: https://doi.org/10.7150/ijbs.49890

[7] M. Zhao, Y. Bai, W. Xie, et al., Interleukin$1 \beta$ level is increased in vitreous of patients with neovascular age-related macular degeneration (nAMD) and polypoidal choroidal vasculopathy (PCV), PLoS ONE 10(5) (2015) e0125150. DOI: https://doi.org/10.1371/journal.pone.012515 $\underline{0}$

[8] N. Kaneko, M. Kurata, T. Yamamoto, et al., The role of interleukin-1 in general pathology, Inflammation and Regeneration 39(12) (2019). DOI: https://doi.org/10.1186/s41232-019-0101-5

[9] IBM Corp. Released, IBM SPSS Statistics for Windows, Version 24.0. Armonk, New York, BM Corp, 2014.

[10] S. Chen, D. Shen, N.A. Popp, et al., Responses of Multipotent Retinal Stem Cells to IL-1 $\beta$, IL-18, or IL-17, Journal of Ophthalmology 369312 (2015) 1-9. DOI: https://doi.org/10.1155/2015/369312

[11] K. Nassar, E. Elfar, J. Lüke, M. Lüke, S. Grisanti, Inflammatory Cytokines in Age Related Macular Degeneration (AMD): Relationships to Disease Activity, Investigative Ophthalmology and Visual Science 54(15) (2013) 141. 